
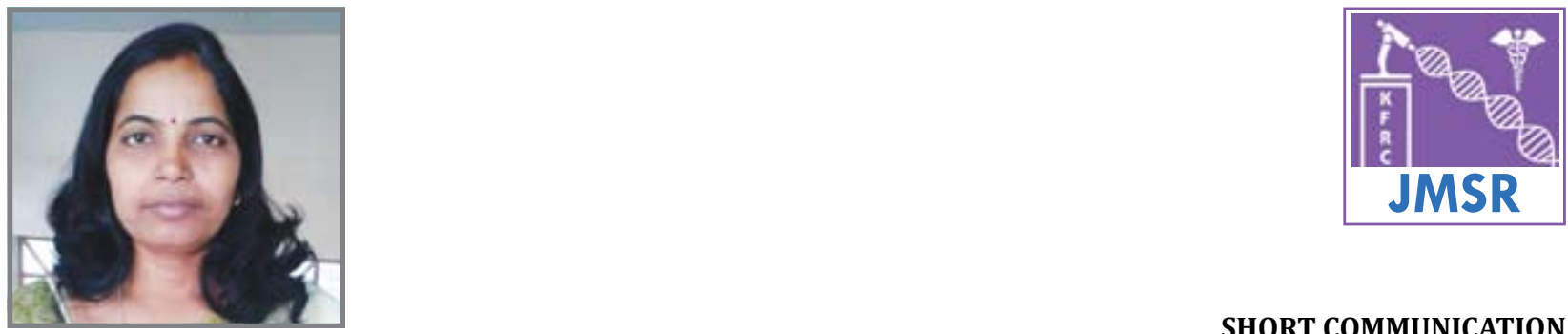

Dr. E. Syamala

SHORT COMMUNICATION

\title{
Effect of physical training on short term memory in school going rural children
}

\author{
Dr. E. Syamala ${ }^{1,2, *}$, T. Rama Kranthi ${ }^{2,}$, Dr. K. Amrutha Kumari ${ }^{2}$, Dr. Simmi Soni ${ }^{2}$, and Dr. Mohamad Nazeer ${ }^{2}$ \\ ${ }^{1}$ Department of Physiology, Krishna Institute of Medical Sciences, Minister Road, Secunderabad, Telangana, India \\ ${ }^{2}$ Dr. V.R.K. Women's Medical College and Research Center, Hyderabad, Telangana, India
}

\begin{abstract}
Background: Short-term memory allows recall for a period of several seconds to a minute without rehearsal. Various studies have shown a positive correlation between physical activity and cognition. The present study is undertaken to find out if physical training has any extra benefit on children's auditory and visual short term memory in rural area whose physical activity is greater than urban children and adults.
\end{abstract}

Materials and methods: Total 60 children participated in the study. 30 children were trained regularly in sports both in the morning and evening at least for 2 hours a day for one year in the age group of 8-16 and 30 untrained children age, gender and BSA matched participated in the study. Auditory memory was tested using numerical and word test. Visual memory was tested using numerical, word and objective tests.

Results and discussion: Statistically significant results were observed in auditory word test, visual numerical, visual word and visual objective tests but auditory numerical test was insignificant.

Conclusions: Short term memory improves linearly with physical activity. This could be due to increase in supply of oxygen and nutrients to brain.

Keywords: Physical activity; Short term memory; Children; Nutrients

*Corresponding authors: Dr. E. Syamala, Department of Physiology, Krishna Institute of Medical Sciences, Minister Road, Secunderabad, Telangana, India. Email: bhupathi.s@rediffmail. com. T. Rama Kranthi, Department of Physiology, Dr. V.R.K. Women's Medical College and Research Center, Hyderabad, Telangana, India. Email: ramakranthy@gmail.com

Received 11 June 2014; Revised 20 August 2014; Accepted 04 September 2014

Citation: Syamala E, Rama Kranthi T, Amrutha Kumari K, Simmi Soni, Mohamad Nazeer (2014) Effect of physical training on short term memory in school going rural children. J Med Sci Res 2(4):228-230. DOI: http://dx.doi.org/10.17727/JMSR.2014/2040

Copyright: (c) 2014 Syamala E, et al. This is an open-access article distributed under the terms of the Creative Commons Attribution License, which permits unrestricted use, distribution, and reproduction in any medium, provided the original author and source are credited.

\section{Introduction}

Physical exercise is a lifestyle factor which increases both physical and mental health throughout life. Short-term memory allows recall for a period of several seconds to a minute without rehearsal. Hippocampus of brain plays a key role in short term memory and in conversion of short term memory to long term memory. It is believed that regular exercise protects hippocampus from stress induced and age related degeneration. Research on animals has shown that exercise increases axon regeneration, neuronal growth, cognitive function, and positively impacts neural systems associated with learning and memory [1]. Various studies have shown a positive correlation between physical activity (PA) and cognition. Physical activity has positive influences 
on concentration, memory and classroom behaviour [2]. As Children are becoming overweight, unhealthy, and unfit, understanding the neurocognitive benefits of an active lifestyle in childhood has important public health and educational implications. The present study is undertaken to find out if physical training has any extra benefit on children's auditory and visual short term memory in rural area whose physical activity is greater than urban children and adults.

\section{Materials and methods}

A total of 60 healthy children of urban and rural with no concerned health problems in the age group of 8-15 years participated in the study. Among 60, 30 children were trained regularly in athletics both in the morning and evening at least for 2 hours a day for one year. Other 30 untrained age, gender and Boy surface area (BSA) matched children were taken as controls. Children with any systemic disease, auditory and/or visual impairment were excluded from the study. Consent was obtained from students, parents and school principal. Study was carried out at ZPHS, Kethepally, Nalgonda district, Telangana, between $9.00 \mathrm{am}$ to $12.00 \mathrm{pm}$. Every student participated in the study, after their regular training and after having breakfast.

\section{Auditory memory test}

Numerical recall test: 20 numbers were read aloud at equal interval within a minute and after a minute, children were asked to recollect the numbers and write down on a paper in 1 minute of time. The procedure was repeated with double and triple numerical. Procedure was simplified for convenience of children and more effective testing [3]. Word recall test procedure was similar to numerical recall test using words.

\section{Visual memory test}

Numerical recall test, Word recall test and Objective recall tests in which numbers, words and objects were focused in front of children and they were asked to recollect and write them down on a paper.

Statistical analysis: Results were analyzed using unpaired " $\mathrm{t}$ " test using MINITAB 14 software.

Results: As per our results, the auditory word and visual word tests were found to be highly significant ( $p$ value: 0.00 and 0.001 ), visual objective and visual numerical tests results were significant $(0.004$ and 0.05). However the auditory numerical test did not give significant results $(0.147)$. Table 1 shows the comparison of values of short term memory tests between athletic and non-athletic children.

Table 1: Comparison of values of short term memory tests between athletic and non-athletic children.

\begin{tabular}{|clccc|}
\hline S. No. & Test & $\begin{array}{c}\text { Group I } \\
\text { Mean } \pm \text { ST. Deviation }\end{array}$ & $\begin{array}{c}\text { Group II } \\
\text { Mean } \pm \text { ST. Deviation }\end{array}$ & P Value \\
\hline 1 & Auditory word & $67.26 \pm 15.16$ & $51.30 \pm 12.77$ & 0.000 \\
2 & Auditory numerical & $39.10 \pm 14.16$ & $34.15 \pm 11.9$ & 0.147 \\
3 & Visual numerical & $18.90 \pm 8.80$ & $14.19 \pm 10.41$ & 0.001 \\
4 & Visual word & $56.45 \pm 21.06$ & $39.67 \pm 19.57$ & 0.004 \\
\hline
\end{tabular}

\section{Discussion}

Present study shows short term memory is more in athletic children. This could be by increasing oxygen and nutrients supply to brain. Our findings are similar to the research done by Hillman et al., who showed physical activity benefits cognition as a whole. Specifically, executive control processes, such as working memory, multitasking or planning are more positively affected. The prefrontal cortex is primarily responsible for supporting executive control processes, and studies suggest exercise may be used as an intervention to prevent age-related decline in executive control and memory [1]. Exercise training increased hippocampal volume by $2 \%$ and effectively reversed age-related loss in volume by 1 to 2 years. Increased hippocampal volume is associated with 
greater serum levels of Brain-derived neurotrophic factor (BDNF), a mediator of neurogenesis in the dentate gyrus [4]. More sustained BDNF levels during learning after intense exercise were related to better short-term learning, whereas absolute dopamine and epinephrine levels were related to better intermediate (dopamine) and long-term (epinephrine) retentions. Thus, BDNF and two of the catecholamines seem to be mediators by which physical exercise improves learning [5]. Bilateral hippocampal volume and neurogenesis mediate the relationship between fitness level (VO2max) and relational memory and spatial memory $[6,7]$. Exercise improves mood and cognition. Physical activity also causes a robust increase in neurogenesis in the dentate gyrus of the hippocampus [8]. Healthy adults engaging in medium intensity exercise have shown that the greatest changes in gray matter takes place within the cingulate cortex, prefrontal cortex, sections of the dorsal anterior cingulate cortex, supplementary motor area, and middle frontal gyrus [9], which are associated in memory and encoding process. Insulin-like growth factor 1 (IGF-1) also plays a role in brain neurogenesis, angiogenesis and neural plasticity. In animals, low serum IGF-1 levels correlated with impaired performance on spatial recognition tasks requiring the hippocampus. [10]. PA increases IGF-1 activity within the brain, and enhances cognitive abilities [11]. Study done by Elwood P et al., showed that men, who exercise regularly had a $59 \%$ reduction in dementia when compared to the men, who didn't exercise regularly [12].

\section{Conclusion}

The present study shows physical education increases short term memory in children. Physical education should be made mandatory in school curriculum and students should not be stressed to read continuously as physical activity increases both physical and mental health which helps in increasing their grades at school.

\section{Conflict of interest}

The authors declare no conflict of interest.

\section{References}

1. Hillman $\mathrm{CH}$, Erickson KI, Kramer AF. Be smart, exercise your heart: exercise effects on brain and cognition. Nat Rev Neurosci. 2008; 9(1):58-65
2. François Trudeau, Roy J Shephard. Physical education, school physical activity, school sports and academic performance. Int J Behav Nutr Phys Act. 2008; 5:10.

3. Kimbrough S, Balkin R, Rancich A. The effect of inverted yoga positions on short-term memory. Athletic insight 2007; $9(2): 34-42$.

4. Erickson KI, Voss MW, Prakash RS. Exercise training increases size of hippocampus and improves memory; PNAS. 2011; 108(7):3017-3022.

5. Winter B, Breitenstein C, Mooren FC, Voelker K. High impact running improves learning. Neurobiol Learn Mem. 2007; 87(4):597-609.

6. Chaddock L, Erickson KI, Prakash RS, Kim JS, Voss MW. A neuroimaging investigation of the association between aerobic fitness, hippocampal volume, and memory performance in preadolescent children. Brain Res. 2010; 1358:172-83.

7. Clark PJ, Brzezinska WJ, Thomas MW. Intact neurogenesis is required for benefits of exercise on spatial memory but not motor performance or contextual fear conditioning in C57BL/6J mice. Neuroscience 2008; 155(4):1048-1058.

8. van Praag H. Neurogenesis and exercise: past and future directions. Neuromolecular Med. 2008; 10(2):128-1240.

9. Ruscheweyh R, Willemer C, Kruger K, Duning T, Warnecke $\mathrm{T}$, et al. Physical activity and memory functions: An interventional study. Neurobiology of Aging 2009; 32: 1304-1319

10. Trejo JI, Piriz J, Llorens-Martin MV, Fernandez AM, Bolos M. Central actions of liver-derived insulin-like growth factor 1 underlying its precognitive effects. Molecular Psychiatry 2007; 12:1118-1128.

11. Gatti R, De Palo EF, Antonelli G, Spinella P. IGF-I/IGFBP system: metabolism outline and physical exercise. J Endocri Invest. 2012; 35:699-707.

12. Elwood P, Galante J, Pickering J, Palmer S, Bayer A, et al. Healthy lifestyles reduce the incidence of chronic diseases and dementia: evidence from the Caerphilly cohort study. PLoS One 2013; 8(12):e81877. 